\title{
First insight into the diversity of snakes in the Pleistocene of Cuba
}

\author{
Elena Syromyatnikova, Ernesto Aranda and Soraida Fiol González \\ Acta Palaeontologica Polonica 66 (2), 2021: 395-407 doi:https://doi.org/10.4202/app.00766.2020
}

The herpetofaunal biodiversity of West Indies suffered a significant change during the last few million years that is well documented for some squamate reptilies (lizards). However, almost nothing is known about past biodiversity of snakes, which are active predators and important component of terrestrial ecosystems. Here we describe the fossil remains of snakes (Reptilia: Serpentes) from the late Pleistocene of El Abrón Cave, Cuba. This is the first representative assemblage of fossil snakes from Cuba. It allows us to evaluate the taxonomic diversity of snakes in the Pleistocene of the island for the first time. The material includes eight taxa from the four snake families: cf. Cubatyphlops (Typhlopidae), Tropidophis melanurus, Tropidophis sp., Cubophis cf. cantherigerus, Arrhyton sp., cf. Caraiba andreae, Dipsadidae indet., and Natricidae indet. (Natricidae). Two (Dipsadidae indet. and Natricidae indet.) are not known in the modern fauna of Cuba. The assemblage from El Abrón Cave shows that ophidian Pleistocene assemblage was different from modern snake fauna of Cuba and was probably more diverse at genus level than it is now. Most of taxa revealed in El Abrón Cave were not previously known in the fossil record.

Key words: Reptilia, Serpentes, insular biodiversity, extinction, Pleistocene, Cuba.

Elena Syromyatnikova [esyromyatnikova@gmail.com], A.A. Borissiak

Paleontological Institute, Russian Academy of Sciences, Profsoyuznaya str., 123, Moscow, 117647 Russia. Ernesto Aranda [earanda@mnhnc.inf.cu] and Soraida Fiol González [sory@mnhnc.inf.cu], Museo Nacional de Historia Natural de Cuba, Obispo 61, Plaza de Armas, Habana Vieja, La Habana, Cuba.

This is an open-access article distributed under the terms of the Creative Commons Attribution License (for details please see creativecommons.org), which permits unrestricted use, distribution, and reproduction in any medium, provided the original author and source are credited. 
Fof Full text $(600.4 \mathrm{kB})$ 